\title{
Strength to the Reseurch Councils' Arms
}

\section{This article, commenting on the Rothschild and Dainton reports, is by Mr William McCall, general secretary of the Institution of Professional Civil Servants.}

My first comment about the present debate on civil science-the government's contribution to it and how it should be managed-is that I hope that it will be the last for some considerable time. For the past decade there has been a virtually non-stop succession of reviews, with hardly a break in the ferment of uncertainty and change. Some but recently established research councils have already been under threat of extinction, and there has been growing criticism of expenditure which cannot be seen to "pay off" quickly and directly. Inevitably, morale has suffered and we urgently need a period of stability.

It is important therefore to ensure that the right decisions are now taken. At the end, not everyone will be satisfied, but there should be no needless controversy about the way in which the decisions are taken. It is essential that all points of view should be carefully assessed. More time for consultation should be given and at this stage an extra month would make a great difference.

My second point is a plea that the dangers of over-simplification should be avoided. In the early stages of the debate the issues have been posed, inevitably perhaps, in terms of Rothschild versus Dainton. The use of colourful language has stimulated the argument but there is a danger that it will not illuminate the issues. Although there is a good deal to be said for the notions underlying it, a customer/contractor relationship is also a dangerous oversimplification. If the issues become posed and polarized in this way the outcome will almost certainly be unsatisfactory. It is a great pity that a joint review was not undertaken by Rothschild and Dainton.

This is not such a fanciful idea as it might appear at first sight. There is, for example, much in the Dainton report with which no informed observer could disagree. Thus, in paragraph 27 , Dainton states:

"the pervasiveness of the conse- quences of science, the diversity of its users, the complexity of the connexions between basic research and related economic benefits, the close relationships between different scientific disciplines, and the unifying importance of training in the methods of research, are, we believe, the most important general points about the nature of the scientific activity that we have to bear in mind in considering the Research Councils".

Later, in paragraphs 30,31 and 32 , the pressure on government resources, the sophistication factor, and the growth of big science are correctly diagnosed as factors which point to increasingly international collaboration, to a need for selectivity in the support of science, and to the need for research councils to become increasingly wellinformed about national needs and objectives. And, as Dainton states in paragraph 32,

"increasingly we need to know more about ways in which such new knowledge can be used in harmony with economic and human needs of the situation and this calls for a much closer integration between the natural sciences and the social sciences ...".

Similarly, we should all be grateful to Lord Rothschild for the way in which he debunks a number of familiar questions about research and development and scientific policy. His idea of a general research surcharge is a valuable one although it will be necessary to make a careful assessment as to whether the figure he suggests is right. His emphasis on the importance of multifunctional laboratories should also meet with general agreement. His various recommendations on staffing policies support and strengthen the recommendations of the Fulton Committee and are appropriate and timely. In particular, he is certainly right about the need to strengthen the scientific competence of many Departments of State.

It is, however, also important not to minimize or to disguise the difference in the approach of these reports. Rothschild appears to shift-responsibility for determining what research should be done to the customer which, in the case of the research councils, will be mainly the appropriate government department. Certainly the "customers" should not be excluded. They do need to be closely involved, but the emphasis should be on involvement and participation. The research councils must and will continue to play the major role in basic science. The working scientist must also participate, and the arrangements should provide for a dialogue at all levels. And disagreements should be brought into the open through annual reports of research councils and of the other government research establishlishments so that decisions are not taken behind the closed doors of government but in a way in which Parliament and the public can exercise some influence.

The argument about organization cloaks the more important argument which is about resources. The issues really relate to the scale of these resources, to priorities, to accountability, and to exploitation. The objective in the exercise should be to maximize resources, accountability and exploitation and to determine priorities acceptable to scientists, Parliament and public.

From the comments which have already been published in various journals and newspapers, it is evident that there is no shortage of prophets of doom. But I do not take such a pessimistic view of the possible outcome of the consultations which are now taking place. It would help if the government would make clear that there is to be no blind cutting back in resources. The future organization must give emphasis to the freedom of the scientist in basic research as well as identify priorities. Scientists, on the other hand. must not jib at arrangements which provide for greater accountability at the same time as it is right to insist that they participate in the decisions which so directly affect them. The government must accept that the research councils and the other public research and development establishments should be fully involved in the decisions on priorities and in maximizing the returns on the investment which the country makes in science, research and development. 